\title{
IV. בltutìnen.
}

feier des 25 jährigen Beftehens der Gođhihhule für Bodenfultur in Wien.

Mit sem Stubientahr 1896/97 hatte bie 5odjintule fitr Bobentultur bas 25. 3afr ibres Beftehens in ibrer gegentwärtigen Beftalt unb zugleid bas expe Sabr in ihrem

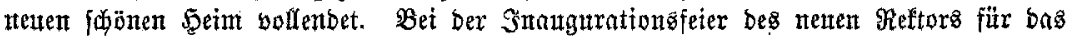
Sabr 1897/98 ant 23. Stober \$. S. Itabm ber abtretende Reftor fofrat Frofefior

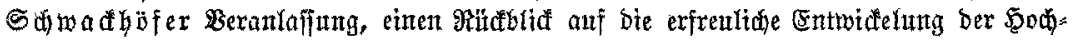

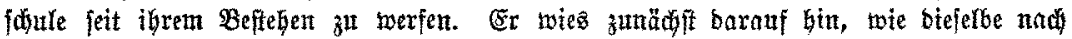

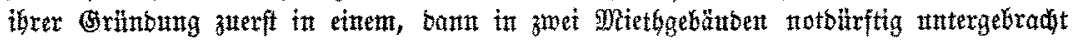
war, bi fe im \$erbfit 1896 ihre eigene ftattlide unb ben jebigen Anforberungen bet

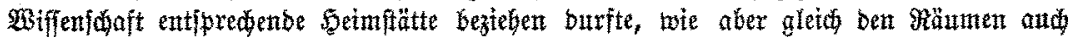
ber Rebrplan eine entipredenbe ungeftaftung uno srweiterung erfabren habe. Sim

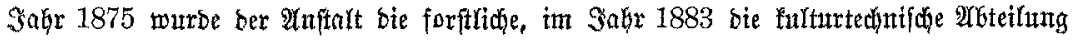

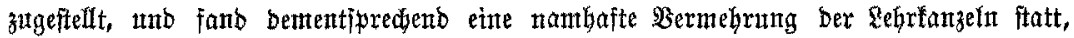

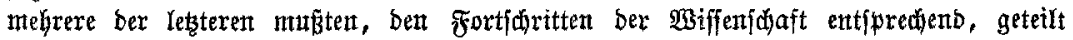

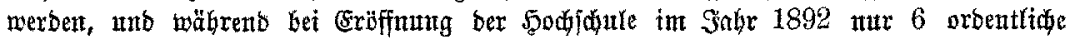
uns anserorbentfide \$rofeforen nebf 8 5onororobanten thätig waren, if jegt bie 3 ahy ber exfteren anf 15, bex lefteren auf 13 geftiegen, unb eine weitere Bermebrung ift in

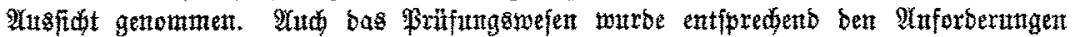

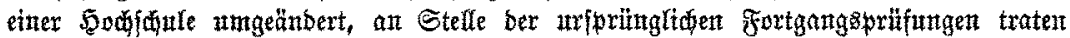
vom Sabr 1878 an bie Diploms: unb von 1882 an bie Staatsprifungeth. - Madbbem

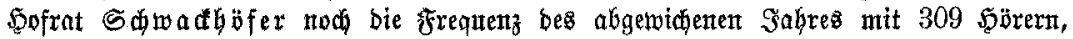

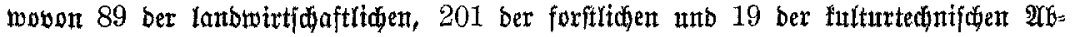
tetlung angebörten, erwähnt uno ber Beräntberungen im Rebrtörper, insbejonbere ehrent ber beiben verforbenten Profefforen Dr. Bgilfen unb Dr. Breitenlobner gebadit,

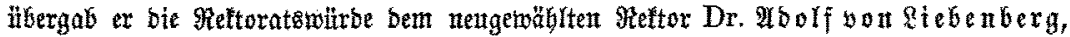
Brofeffor bex lanbwirtfolaftltaen Bf(cmenturobuttionstehre.

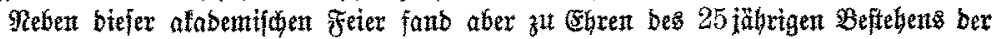

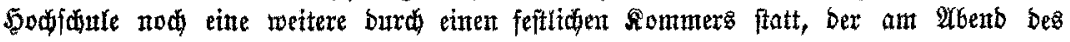

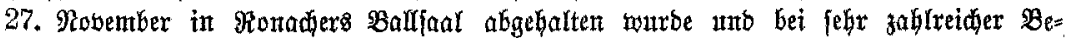

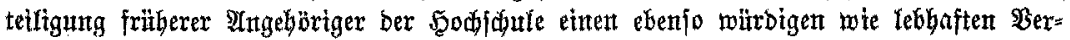

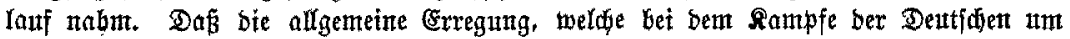

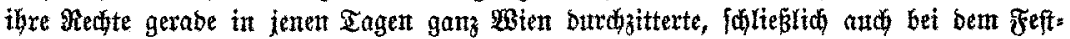

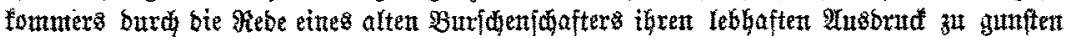

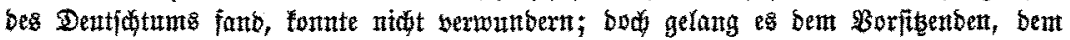

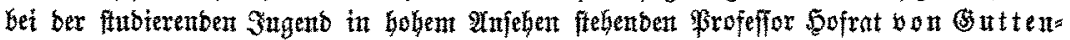

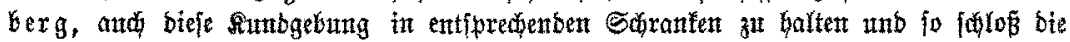
fodjüte Feier ofyte Miffint.

\section{Die Witterung der Fommeñden Jahre.}

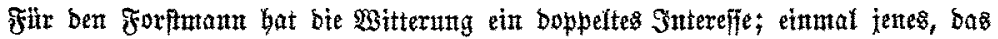

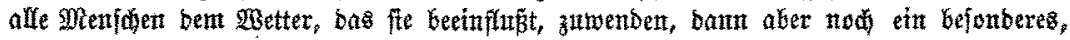
bas ber Sorge un fetne Wfleglinge in Walbe entfpritugt. Gouren wir bie Brophezetungen

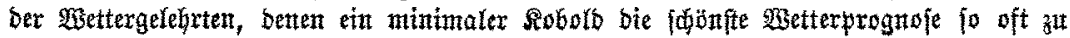
2isaffer werbet läbt! 